\title{
Effect of Chitosan Nanocomposite Film Cross linked with Quercetin on Quality and Shelf Life Extension of Paneer
}

\author{
M. Sahityarani*, E. Naga Mallika, B. Eswara Rao, \\ T. Srinivasa Rao and D. Narendranath \\ Department of Livestock products technology, NTR college of Veterinary Science, \\ Srivenkateswara Veterinary University, Gannavaram, India \\ *Corresponding author
}

\section{A B S T R A C T}

\section{Keywords}

Chitosan, crosslinking agent, Paneer, Quercetin and Shelf life

\section{Article Info}

Accepted:

14 June 2020

Available Online:

10 July 2020
The objective of this study was to investigate the effect of chitosan (CS) nanocomposite films incorporated with quercetin (3 wt. \%) as crosslinking agent on quality and shelf life of paneer stored at $4 \pm 1^{\circ} \mathrm{C}$. The microbiological, physicochemical ( $\mathrm{pH}$, Thiobarbituric acid-reactive substances values, Tyrosine values) and sensory qualities were measured on all the samples. Packaging with CS-quercetin nanocomposite film retarded the increase in TBARS values, Tyrosine values and Total plate count. A microbiological shelf-life extension of average of 8 days for paneer was achieved for CS-quercetin group when compared to the control group. CS-quercetin nanocomposite composite film maintained acceptable sensory quality of paneer throughout the storage period. The results indicated that CS-quercetin nanocomposite composite film could be used as a packaging film for extending the shelf life of Paneer.

\section{Introduction}

Milk products plays major role in human diet as they deliver protein efficiently. They contain high amount of nutrients and are susceptible to the microbial spoilage. Hence, preservation of the milk products for a longer time has been of interest to producers and processors. Packaging is a co-ordinated system of enclosing food to protect them from contamination of physical, chemical and biological sources. Most commonly used packaging material are made of polyethylene (PE) and polyvinyl chloride (Teasdale et al., 2015). These plastics can enter the food chain and reach the humans through bioaccumulation and also aggravate toxicological effects on marine life. The demand of consumers for higher quality and longer shelf life foods, while reducing disposable packaging materials and increasing recyclability increased the interest in edible and bio-degradable films. These are made from polysaccharides, proteins, and lipids, however their use is limited as they exhibit poor mechanical properties (e.g. low tensile strength), high hygroscopic capacity, rigidity, brittle character, and barrier properties (e.g. high water permeability). Thus the use of nanoparticles and formation of 
nanocomposite showed an increase in barrier properties as they create the "tortuous pathway "mechanism that was able to improve the barrier properties. Active packaging incorporated with natural antioxidants and/or antimicrobial agents which serve as a barrier for reducing modifications in color and texture, or loss of chemical, microbiological and sensory quality could be used as alternative emerging technology to enhance the shelf life of food products (Chamanara et al., 2012).

Chitosan, a heteropolysaccharide is produced by the alkaline deacetylation of chitin can form stable, flexible and tough films and also possesses valuable properties (biocompatible, biodegradable, antibacterial nature and film forming ability) promoting its use in a variety of interesting applications. The wide antimicrobial activity of chitosan is due to its polycationic nature (Arora et al., 2016). Due to the presence of very large number of pendant groups such as (amino) $\mathrm{ANH}_{2}$ and (hydroxyl) $\mathrm{AOH}$, it can accommodate new functional materials in its matrix paving the way for enhanced properties (Dutta et al., 2009).

Plant polyphenols contain sufficient hydroxyl groups and other groups, such as carboxyl groups, which can effectively cross-link with the polymers. These include quercetin, ferulic, tannic acid, genipin and citric acid. Quercetin is of the most abundant flavonoids which has ortho-diphenol structure (Braga et al., 2019). This polyphenol has been the object of multidisciplinary studies due to its antioxidant, anti-inflammatory, anticarcinogenic, and antiviral properties, antimicrobial and acting as a free-radical scavenger or metal ions chelating agent (Souza et al., 2015). Therefore, incorporation of quercetin in polymer films had demonstrated good results in the reduction of lipid oxidation and control of microbial growth in foods. Besides, the addition of active agents in the polymeric matrix of films, it can influence the mechanical, thermal, optical and gas barrier properties of the packaging. Quercetin has been incorporated into several different films, such as zein, chitosan, chitosan-gelatin, kafirin and carboxymethyl cellulose films successfully.

The objective of the present work was to determine the effectiveness of chitosan nanocomposite films crosslinked with quercetin, in paneer as measured by microbiological (Total plate count), physicochemical $\mathrm{pH}$, thiobarbituric acid reactive substances (TBARS), Tyrosine Value (TV), and sensory qualities during refrigerated storage.

\section{Materials and Methods}

\section{Preparation of Chitosan Quercetin nanocomposite film}

Chitosan (2\% w/v) and agar (4 wt.\%) was used in the development of nanocomposite film. Chitosan was dissolved in $2 \%(\mathrm{v} / \mathrm{v})$ aqueous glacial acetic acid solution under continuous magnetic stirring without heating. Agar was dispersed in distilled water and the formed coarse solutions were subjected to ultrasonication (Qsonica, Q500, USA) at 20 $\mathrm{kHz}, 200$ watts $20 \mathrm{~mm}$ diameter probe for 5 minutes for formation of nanosolutions. The nanocomposite films were prepared by adding agar nanosolution to chitosan nanosolution under continuous magnetic stirring, at $90^{\circ} \mathrm{C}$. The solution was then cooled to $70^{\circ} \mathrm{C}$ and glycerol was added as plasticizer $(5 \%)$ to the solution. Then the cross linking agent quercetin (3wt \%) was incorporated and allowed to crosslink for 1hour under continuous magnetic stirring. The nanocomposite film formed from the film forming solution without addition of cross linking agent was taken as control film. 
Finally, the solution mixtures were casted into a Petri plate of 9 centimetres diameter and dried at $60^{\circ} \mathrm{C}$ to evaporate the solvent for the formation of respective nanocomposite films. After drying, the nanocomposite films were peeled off and stored in desiccator for further study.

Nanosolution of Chitosan was added with 4 percent nano agar solution at a volumetric ratio of $1: 1$ under continuous stirring at $90^{\circ} \mathrm{C}$. The nanocomposite solutions of ChitosanAgar were allowed to cool to $70^{\circ} \mathrm{C}$. Glycerol was added at 5\% level as plasticiser. Quercetin at three percent level was added into Chitosan-Agar nanocomposite solution to act as crosslinking agent and was allowed to crosslink for 60 minutes under continuous stirring (Spinot Model MC-02), thus forming Chitosan quercetin biodegradable nanocomposite film forming solutions.

The nanocomposite film formed from the film forming solution without addition of cross linking agent was taken as control film. The nanocomposite film forming solutions, thus formed were casted on to petri plates and dried at $60^{\circ} \mathrm{C}$. Calcium chloride solution at 2 percent (w/v) level was added into each film forming solution just before casting of the films.

\section{pH}

$\mathrm{pH}$ of the preparation was determined by following the method of Trout et al (1992) using deluxe digital $\mathrm{pH}$ meter (model 101E). $5 \mathrm{~g}$ of representative sample was homogenized with $45 \mathrm{ml}$ of distilled water in a laboratory blender for about one minute. The $\mathrm{pH}$ was recorded by immersing the combination glass electrode of digital $\mathrm{pH}$ meter in the homogenate. Before the measurement of $\mathrm{pH}$, the $\mathrm{pH}$ meter was calibrated with buffer solutions of $\mathrm{pH} 4$ and $\mathrm{pH} 7$ as per user manual instructions to avoid errors.

\section{Thiobarbituric acid Reactive Substances (TBARS) Value}

TBARS values were determined by the method of Tarladgis et al (1960). 10g of sample was blended with $50 \mathrm{ml}$ of distilled water in a waring blender for 2 minutes. This mixture was transferred to a $500 \mathrm{ml}$ Kjeldahl flask quantitatively. Then the blender was rinsed with $45 \mathrm{ml}$ of distilled water and was transferred quantitatively to the flask to which $5 \mathrm{ml}$ of $\mathrm{HCl}$ was added previously. Few glass beads were added to the contents to avoid frothing and bumping. The contents of the flask were heated to $80-100^{\circ} \mathrm{C}$ with the help of a heating mantle and $50 \mathrm{ml}$ of distillate was collected in a stoppered measuring cylinder. $5 \mathrm{ml}$ of thoroughly mixed distillate was pipetted out in duplicates into $20 \mathrm{ml}$ glass stoppered test tubes to which $5 \mathrm{ml}$ of $0.02 \mathrm{M}$ TBA reagent was added. The contents were mixed well and heated in a boiling water bath for 35minutes. A blank consisting of $5 \mathrm{ml}$ of distilled water and $5 \mathrm{ml}$ TBA reagent was run simultaneously. After cooling the tubes under running water, optical density (OD) was measured in a Thermoscientific Nanodrop 2000c Spectrophotometer at $532 \mathrm{~nm}$.

\section{TBARS value(mg of malonaldehyde per $\mathrm{kg}$ of sample $)=0 D \times 7.8$}

Where,

OD - Optical Density at $532 \mathrm{~nm}$.

\section{Tyrosine Value}

It was determined based on the procedure of Strange et al (1977). Trichloroacetic acid (TCA) extract of sample was prepared by homogenizing $4 \mathrm{~g}$ of sample with $20 \mathrm{ml}$ of pre cooled 20 percent TCA solution for $2 \mathrm{~min}$ with the help of mortar and pestle. The contents were filtered through Whatman No.42 (Diameter $125 \mathrm{~mm}$ ) in a $100 \mathrm{ml}$ conical 
flask. $2.5 \mathrm{ml}$ of TCA extract was mixed with equal amount of distilled water and $10 \mathrm{ml}$ of $0.5 \mathrm{~N}$ sodium hydroxide solution. The mixture was kept for $10 \mathrm{~min}$ followed by the addition of $3 \mathrm{ml}$ of Folin and Ciocalteu's (FC) phenol reagent (1 volume of concentrated FC reagent and 2 volumes of distilled water).

The contents were mixed thoroughly and kept in dark for 30 minutes at room temperature and absorbance was measured at $730 \mathrm{~nm}$ using Thermoscientific Nanodrop 2000c spectrophotometer. For blank same procedure was followed as described above except that 5 $\mathrm{ml}$ of 20 percent chilled TCA solution was added instead of TCA extract and distilled water. By reference to the standard graph, the tyrosine value was calculated as $\mathrm{mg}$ of tyrosine per100 $\mathrm{g}$ of sample.

\section{Total Plate Count}

The microbial quality was evaluated by estimating the Total plate count (TPC) following pour plating technique as per standard procedure of ICMSF (1986). For microbiological analysis, $5 \mathrm{~g}$ of representative sample was homogenized with $45 \mathrm{ml}$ of 0.1 percent sterile peptone water in laboratory blender and tenfold serial dilutions were made from each sample by using 1 percent peptone water as diluent. Sterile petri plates were inoculated aseptically with $1 \mathrm{ml}$ sample from appropriate dilution in duplicates. $15-20 \mathrm{ml}$ of sterilized and plate count agar (Himedia, Mumbai) at $44-46^{\circ} \mathrm{C}$ was poured into petri plates gently and the contents were mixed well for even distribution of the sample without air bubbles and plates were allowed for some time to solidify. The plates were then incubated in inverted positions at $37^{\circ} \mathrm{C}$ for 24-48 hrs. Plates having 25-250 colonies were selected and the colonies were counted. The results were expressed as log units per gram of the sample.

\section{Sensory Evaluation}

A six member experienced panel of judges consisting of scientists and students (postgraduate and doctoral) of Department of Livestock Products Technology, NTR college of veterinary science, Gannavaram evaluated the sensory quality such as colour and appearance, flavour, body and texture and overall acceptability using 9-point descriptive scale for paneer according to Rajkumar et al., (2010) with slight modification.

\section{Statistical Analysis}

The data were subjected to statistical analysis by applying t- test for unequal variances using Statistical Package for Social Sciences (SPSS), the $25^{\text {th }}$ version $(n=6)$. Differences between means were tested using Duncan's (1951) multiple comparison test and the significance was set at $\mathrm{P}<0.05$.

\section{Results and Discussion}

\section{pH}

The changes in $\mathrm{pH}$ values of paneer during refrigerated storage were given in Table 1. The overall mean $\mathrm{pH}$ values of each group showed decreased throughout the 20 days of refrigerated storage. The decreased $\mathrm{pH}$ values might be due to the accumulation of lactic acid synthesised by Lactobacillus spp. (Dermiki et al., 2008) and production of acidic amino acids and free fatty acids by proteolysis and lipolysis. The mean $\mathrm{pH}$ values of paneer samples wrapped in control film were slightly lower than those wrapped in CSquercetin nanocomposite film, probably the acid coagulation of milk might have furnished a higher hydrogen ion concentration in the final product. Similar trend was observed by Mendiratta et al (2007) in citric acid treated paneer samples. The results obtained in the present study were in accordance with Das et al., (2018) who reported the decreased $\mathrm{pH}$ 
values in paneer treated with crude extracts and Pierro et al (2011) in Ricotta cheese coated with a chitosan/whey protein edible film.

\section{TBARS}

Values of TBARS (expressed as $\mathrm{mg}$ of malonaldehyde $/ \mathrm{kg}$ of the sample) were shown in Table 1. Over all, the mean TBARS values increased from $0^{\text {th }}$ day to $20^{\text {th }}$ day of refrigerated storage period. The mean TBARS values of paneer wrapped with CS-quercetin $3 \%$ nanocomposite film were significantly $(\mathrm{p}<0.05)$ lower than the control film wrapped paneer samples throughout the storage period, which might be due to the incorporation of quercetin, a natural antioxidant as cross linking agent have retarded the lipolytic changes. Similar findings were observed by Ahmed et al (2013) in Kaladhi and Das et al (2018) in paneer during refrigerated storage studies.

Table.1 Effect of chitosan quercetin based films on the physico-chemical parameters of paneer during refrigerated $\left(4 \pm 1^{\circ} \mathrm{C}\right)$ storage

\begin{tabular}{|c|c|c|c|c|c|c|c|c|}
\hline \multirow[t]{2}{*}{ Days } & \multicolumn{2}{|c|}{ pH } & \multicolumn{2}{|c|}{$\begin{array}{c}\text { TBARS } \\
\text { (mg malonaldehyde/ } \\
\text { kg of product) }\end{array}$} & \multicolumn{2}{|c|}{$\begin{array}{c}\text { Tyrosine value } \\
\text { (mg/100g product) }\end{array}$} & \multicolumn{2}{|c|}{$\begin{array}{l}\text { Total plate count } \\
\left(\log _{10} \mathrm{cfu} / \mathrm{g} \text { of product }\right)\end{array}$} \\
\hline & Control & $\begin{array}{l}\text { CS- } \\
\text { quercetin } \\
\text { film }\end{array}$ & Control & $\begin{array}{l}\text { CS- } \\
\text { quercetin } \\
\text { film }\end{array}$ & Control & $\begin{array}{l}\text { CS- } \\
\text { quercetin } \\
\text { film }\end{array}$ & Control & $\begin{array}{l}\text { CS- } \\
\text { quercetin } \\
\text { film }\end{array}$ \\
\hline 0 & $5.83 \pm 0.02$ & $5.83 \pm 0.03$ & $0.24 \pm 0.01$ & $0.24 \pm 0.01$ & $11.48 \pm 0.04$ & $11.47 \pm 0.06$ & $3.25 \pm 0.01$ & $3.24 \pm 0.01$ \\
\hline 4 & $5.76 \pm 0.02$ & $5.77 \pm 0.02$ & $0.34 \pm 0.01$ & $0.28 \pm 0.01$ & $17.44 \pm 0.16$ & $13.44 \pm 0.19$ & $3.35 \pm 0.02$ & $3.28 \pm 0.01$ \\
\hline 8 & $5.71 \pm 0.01$ & $5.72 \pm 0.02$ & $0.75 \pm 0.01$ & $0.62 \pm 0.01$ & $25.59 \pm 0.19$ & $19.51 \pm 0.16$ & $3.84 \pm 0.01$ & $3.39 \pm 0.02$ \\
\hline 12 & $5.67 \pm 0.02$ & $5.67 \pm 0.02$ & $1.06 \pm 0.02$ & $0.92 \pm 0.02$ & $32.63 \pm 0.15$ & $27.57 \pm 0.20$ & $4.20 \pm 0.02$ & $3.51 \pm 0.02$ \\
\hline 16 & $5.61 \pm 0.02$ & $5.59 \pm 0.01$ & $1.69 \pm 0.02$ & $1.17 \pm 0.03$ & $44.55 \pm 0.20$ & $32.98 \pm 0.28$ & $4.62 \pm 0.01$ & $4.06 \pm 0.02$ \\
\hline 20 & $5.49 \pm 0.02$ & $5.49 \pm 0.02$ & $2.56 \pm 0.04$ & $1.80 \pm 0.03$ & $53.86 \pm 0.23$ & $45.31 \pm 0.32$ & $5.87 \pm 0.01$ & $4.58 \pm 0.02$ \\
\hline
\end{tabular}

Table.2 Effect of chitosan quercetin based films on sensory quality of paneer during refrigerated storage

\begin{tabular}{|l|l|c|c|c|c|c|c|}
\hline \multirow{2}{*}{ Colour } & \multicolumn{2}{|c}{$0^{\mathrm{Ns}}$} & $4^{*}$ & $8^{*}$ & $12^{*}$ & $16^{*}$ & $20^{*}$ \\
& Control & $8.84 \pm 0.02$ & $8.41 \pm 0.02$ & $7.74 \pm 0.03$ & $7.22 \pm 0.01$ & $6.88 \pm 0.02$ & $6.04 \pm 0.05$ \\
\hline & $\begin{array}{l}\text { CS-quercetin } \\
\text { film }\end{array}$ & $8.87 \pm 0.02$ & $8.61 \pm 0.02$ & $8.00 \pm 0.03$ & $7.54 \pm 0.02$ & $7.11 \pm 0.02$ & $6.42 \pm 0.03$ \\
\hline Flavour & Control & $8.43 \pm 0.02$ & $7.97 \pm 0.04$ & $7.75 \pm 0.02$ & $7.25 \pm 0.03$ & $6.65 \pm 0.06$ & $5.89 \pm 0.02$ \\
\cline { 2 - 8 } & $\begin{array}{l}\text { CS-quercetin } \\
\text { film }\end{array}$ & $8.45 \pm 0.02$ & $8.11 \pm 0.02$ & $7.99 \pm 0.03$ & $7.76 \pm 0.02$ & $7.10 \pm 0.01$ & $6.28 \pm 0.04$ \\
\hline $\begin{array}{l}\text { Body and } \\
\text { Texture }\end{array}$ & Control & $8.58 \pm 0.02$ & $8.30 \pm 0.04$ & $8.15 \pm 0.01$ & $7.89 \pm 0.03$ & $6.98 \pm 0.04$ & $6.25 \pm 0.03$ \\
\hline $\begin{array}{l}\text { CS-quercetin } \\
\text { film }\end{array}$ & $8.57 \pm 0.02$ & $8.53 \pm 0.01$ & $8.48 \pm 0.02$ & $8.19 \pm 0.02$ & $7.63 \pm 0.02$ & $7.23 \pm 0.02$ \\
\hline $\begin{array}{l}\text { Overall } \\
\text { acceptability }\end{array}$ & Control & $8.70 \pm 0.03$ & $8.00 \pm 0.02$ & $7.49 \pm 0.02$ & $7.13 \pm 0.02$ & $6.44 \pm 0.03$ & $6.00 \pm 0.02$ \\
\cline { 2 - 8 } & $\begin{array}{l}\text { CS-quercetin } \\
\text { film }\end{array}$ & $8.74 \pm 0.03$ & $8.25 \pm 0.02$ & $7.96 \pm 0.02$ & $7.56 \pm 0.02$ & $7.12 \pm 0.02$ & $6.67 \pm 0.03$ \\
\hline
\end{tabular}


Fig.1 Effect of chitosan-based films on the $\mathrm{pH}$ of paneer during refrigerated storage

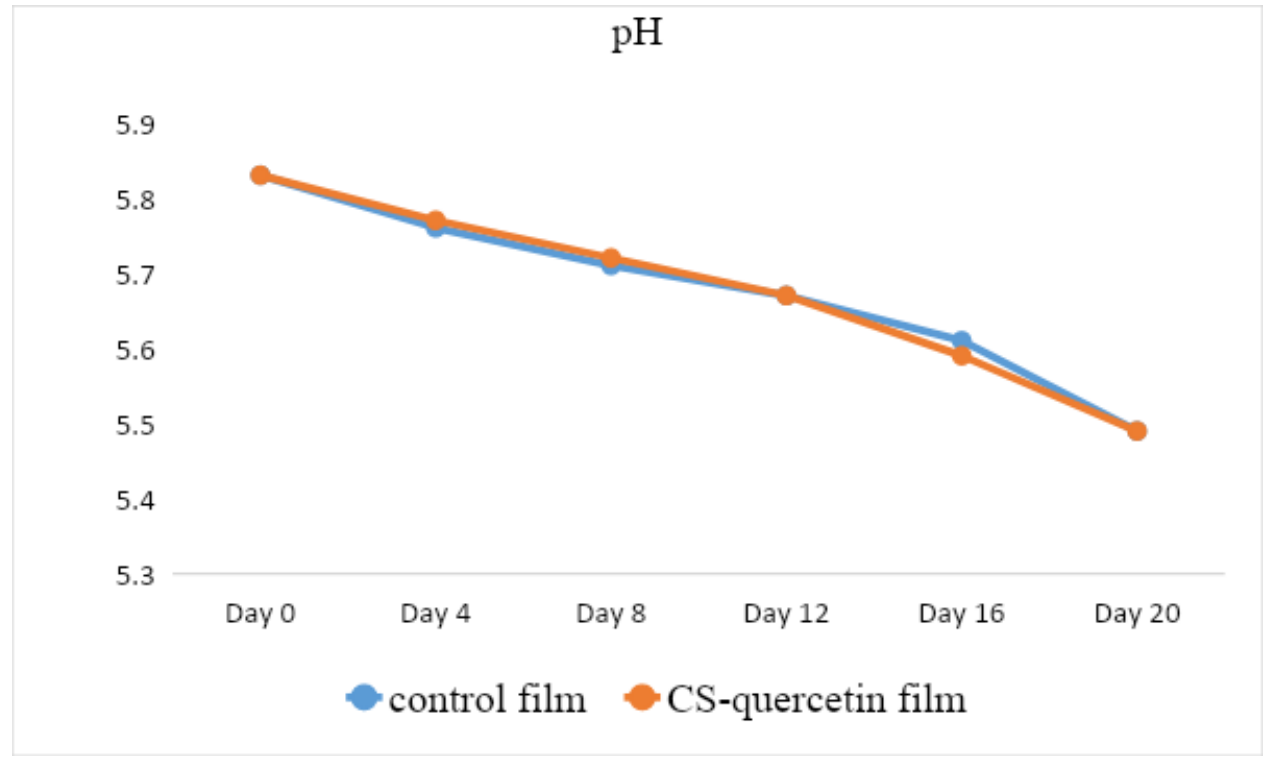

\section{Tyrosine value}

The tyrosine content of paneer samples wrapped with CS-quercetin $3 \%$ were significantly $(\mathrm{P}<0.05)$ lower than control film wrapped samples (Table 1). The values increased from an initial 11.26 to 45.21 in 20 days with CS-quercetin film and 11.42 to 53.42 with control films, respectively. The increase in tyrosine content of samples with the increase in storage period might be due to the growth of microorganisms and accumulation of metabolites. The lower values in samples wrapped with CS-quercetin $3 \%$ nanocomposite film might be related to the antimicrobial activity of quercetin in the CS- quercetin nanocomposite film. The results were in concomitant values reported by Khatkar et al., (2017) in paneer treated with plant essential oils.

\section{Total plate count}

The result of the microbiological analyses of paneer samples during the 20 days of refrigerated storage period was presented in Table 1. The total plate counts of control film samples increased steeply with the increase in storage period mostly due to more availability favourable condition for the growth of a wide variety of organisms in stored product. The paneer samples wrapped in CS-quercetin 3\% showed significantly $(\mathrm{P}<0.05)$ lower values than those of control film samples. The interference of phenolic hydroxyl groups of Quercetin with the vital functionalities that were related to the survivability of microorganisms might be the reason for reduction in total plate count of the paneer wrapped in treated film than control film (Rauha et al., 2000 and Souza et al., 2015). The results of present study were in line with Pierro et al (2011) in Ricotta cheese coated with a chitosan/whey protein edible film and Khatkar et al., (2017) in paneer treated with plant essential oils.

\section{Sensory evaluation}

The mean sensory scores with respect to colour and appearance, flavour, body and texture of paneer samples wrapped in CSquercetin $3 \%$ were comparatively higher than the samples wrapped in chitosan nanocomposite film (Table 2). This had reflected in higher overall acceptability scores 
for paneer wrapped in quercetin treated film. Overall, the mean values of sensory attributes (colour, flavour, body and texture and overall acceptability) of paneer samples decreased significantly $(\mathrm{P}<0.0 .5)$ in both treatment and control groups with increase in refrigerated storage period. The oxidation of lipids along with degradation of proteins due to the growth of microorganisms might have resulted in subsequent dehydration of the product. No significant differences in visual appearance, flavour, body and texture between control film and CS-quercetin 3\% film wrapped paneer samples were detected during storage period. Furthermore, CS-quercetin 3\% paneer samples maintained its body and texture, overall acceptability better than the control samples suggesting that CS-quercetin 3\% film could be helpful to overcome the problem of limited shelf life of paneer by maintaining the physico-chemical and sensory attributes. The results were in accordance with Pierro et al (2011) in Ricotta cheese coated with a chitosan/whey protein edible film and Khatkar et al., (2017) in paneer treated with plant essential oils.

In conclusion the results of this study demonstrated the effectiveness of chitosan nanocomposite film crosslinked with quercetin $3 \%$ for $1 \mathrm{hr}$ on antimicrobial properties and lipid oxidation of paneer during refrigerated storage of 20 days. Chitosan nanocomposite films crosslinked with quercetin has potential to meet consumer demand for foods without chemical preservatives and can be a good active packaging for extending the shelf life of paneer.

\section{Acknoledgements}

NTR College of Veterinary Science, Sri Venkateswara Veterinary University, Gannavaram.

\section{References}

Ahmad SR, Pathak V, Bhat ZF, Bukhari SAA (2014) Effect of sorbic acid on the storage quality of Kaladhi, an acid coagulated milk product. Journal of Food Science and Technology 51(12):4040-4046.

Arora D, Sharma N, Sharma V, Abrol V, Shankar R and Jalgan 2016 An update on Polysaccharide based nanomaterials for antimicrobial applications. Appl. Microbiol. Biotechnol. 100(6), 26032615.

Braga LR, Leonardo M P, Soazo MV, Machado F (2019) Evaluation of the antimicrobial, antioxidant and physicochemical properties of Poly (Vinyl chloride) films containing quercetin and silver nanoparticles. LWT - Food Science and Technology 101:491-498.

Chamanara V, Shabanpour B, Gorgin S and Khomeir M 2012 An investigation on characteristics of rainbow trout coated using chitosan assisted with thyme essential oil International Journal of Biological Macromolecules Vol. 50 (3): 540-544

Das A, Chauhan G, Agrawal R K, Tomar S, Sirajuddin, Satyaprakash K (2018) Comparative Study on Evaluation of Refrigerated $\left(4 \pm 1^{\circ} \mathrm{C}\right)$ Storage Stability of Paneer Incorporated with Crude Extract from Indian Curd, Nisin and Lactic

Acid. Int.J.Curr.Microbiol.App.Sci 7(4):167180.

Dermiki M, Ntzimani A, Badeka A, Savvaidis IN, Kontominas MG (2008) Shelf-life extension and quality attributes of the whey cheese "Myzithra Kalathaki" using modified atmosphere packaging. LWT-Food Science and Technology 41:284-294.

Dutta PK, Tripathi S, Mehrotra GK, Dutta J 
(2009) Food Chemistry 114:11731182.

ICMSF (1986) Sampling for microbiological analysis: Principles and scientific applications (2nd ed.) Toronto, Canada: International Commission on Microbiological Specifications for Foods.

Khatkar AB, Ray A, Kaur A (2017) Studies on Shelf Life Extension of Paneer with the Addition of Plant Essential Oil and Different Packaging Materials. Int.J.Curr.Microbiol.App.Sci 6(9):376389

Mendiratta SK, Keshri RC, Yadav PL, Sanyal MK (2007) Quality of skim milk paneer prepared by using combination of coagulants and preservatives. In: Proceedings of the International Conference on Traditional Dairy Foods, NDRI, Karnal, India, 14-17 November pp. 112.

Pierroa PD, Sorrentino A, Mariniello L, Giosafatto CVL, Porta R (2011) Chitosan/whey protein film as active coating to extend Ricotta cheese shelflife. LWT - Food Science and Technology 44:2324-2327.

Rajkumar S N, Sudheer B and Geevenghese P I 2010 Studies on the sensory evaluation of calcium fortified paneer. International Journal of Agriculture Food Science and Technology. 1: 1-5.

Souza MP, Vaz AFM, Silva HD, Cerqueira MA, Vicente AA, Carneiro MG (2015) Development and Characterization of an Active Chitosan-Based Film Containing Quercetin. Food Bioprocess Technol.

Strange ED, Benedict RC, Smith JL, Swift CE (1977) Evaluation of Rapid Tests for Monitoring Alterations in Meat Quality During Storage. Journal of Food Protection 40(12):843-847.

Teasdale A, Jahn M, Bailey S, Feilden A, Taylor G, Corcoran ML, Malick R, Jenke D, Stults CL, Nagao LM (2015) Controlled Extraction Studies Applied to Polyvinyl Chloride and Polyethylene Materials: Conclusions from the ELSIE Controlled Extraction Pilot Study. AAPS PharmSciTech. 16:1-11. [CrossRef]

Trout E S, Hunt N C, Jhonson D E, Claus J R, Kastner C L and Krop D H 1992 Chemical, physical and sensory characterization of ground beef containing 5 to $30 \%$ fat. Journal of food science 57: 25-29.

\section{How to cite this article:}

Sahityarani, M., E. Naga Mallika, B. Eswara Rao, T. Srinivasa Rao and Narendranath, D.. 2020. Effect of Chitosan Nanocomposite Film Crosslinked with Quercetin on Quality and Shelf Life Extension of Paneer. Int.J.Curr.Microbiol.App.Sci. 9(07): 1543-1550. doi: https://doi.org/10.20546/ijcmas.2020.907.178 